\title{
HUBUNGAN KEMAMPUAN GURU DALAM MENGELOLA KELAS DENGAN PROSES BELAJAR MENGAJAR PADA MATA PELAJARAN SEJARAH KEBUDAYAAN ISLAM (SKI) DI MTS NEGERI BATURAJA
}

\author{
Azhar \\ Program Studi Manajeman, STIE Musirawas Lubuklinggau \\ azharplaju75@gmail.com
}

\begin{tabular}{ll}
\hline & Abstrak \\
\hline Article History & The quality of life of the nation is largely \\
Received : 15-03-2019 & determined by educational factors. In \\
Revised : 25-06-2019 carrying out this research, the author & accepted:01-07-2019 \\
Ases quantitative research methods. \\
\hline Keywords : Teacher quantitative approach, descriptive \\
Ability, Teaching and analysis through library research and \\
Learning Process \\
field research. The results teacher's \\
ability to manage classes in MTs Negeri \\
Baturaja is in the moderate category \\
45.62\%. means to be quite good because \\
it is supported by the sincerity of teachers \\
in providing religious understanding and \\
guidance to these students. The results of \\
the next study can be concluded that the \\
teaching and learning process in the \\
subjects of Islamic Culture History (SKI) \\
in Baturaja State MTs is in the moderate \\
category 59.65\%. that the teaching and \\
learning process in Islamic Culture \\
History (SKI) subjects at Baturaja State \\
MTs seems to be quite good because it is \\
supported by positive student habits and \\
activities.
\end{tabular}

\section{Pendahuluan}

Kualitas kehidupan bangsa sangat ditentukan oleh faktor pendidikan. Peran pendidikan sangat penting untuk menciptakan kehidupan yang cerdas, damai, terbuka dan demokratis. Oleh karena itu, pembaruan pendidikan harus selalu dilakukan untuk meningkatkan kualitas pendidikan nasional. Ada tiga faktor yang 
menyebabkan mutu pendidikan tidak mengalami perubahan secara merata. Faktor pertama kebijakan dan penyelenggaraan pendidikan nasional menggunakan pendekatan education production function atau input-output analysis yang tidak dilaksanakan secara konsekuen. Faktor kedua, penyelenggaraan pendidikan nasional dilakukan secara birokratik-sentralitik. Faktor ketiga, peran serta masyarakat khususnya orang tua siswa dalam penyelenggaraan pendidikan selama ini sangat minim.Hasil studi yangdilakukan Direktorat Dikmenum mengenai pola pembelajaran dan pemahaman siswa menyimpulkan bahwa proses pembelajaran cenderung Text Book Oriented dan tidak terkait dengan kehidupan sehari-hari. Keberadaan geografi dalam stuktur program pengajaran di sekolah sangat penting karena geografi memberikan pengetahuan, pembentukan nilai dan sikap, serta ketrampilan kepada siswa secara langsung berinteraksi dengan lingkungan.Dalam hal ini, konteks pembaruan pendidikan yang perlu disoroti, yaitu pembaruan kurikulum, peningkatan kualitas pembelajaran dan efektivitas metode pembelajaran. Kurikulum pendidikan harus komprehensif dan responsif terhadap dinamika sosial, relevan, tidak overload, mampu mengakomodasikan keberagaman keperluan dan kemajuan teknologi.

Berbagai usaha telah dilakukan Depdiknas untuk memperbaiki mutu pendidikan nasional. Salah satunya adalah diberlakukannya Kurikulum,dikembangkan untuk memberikan keterampilan dan kecakapan bertahan hidup kepada siswa dalam menghadapi perubahan, ketidak-pastian dan kerumitan-kerumitan dalam kehidupan. Kurikulum ini ditujukan untuk menciptakan tamatan yang kompeten dan cerdas dalam membangun identitas budaya dan bangsa. Guru dan kurikulum merupakan dua aspek pendidikan yang sangat menentukan keberhasilan pendidikan itu sendiri.Sebuah pendidikan yang dilaksanakan dimanapun tidak akan pernah mencapai suatu hasil yang optimal tanpa adanya guru dan kurikulum yang baik.Dalam hal ini guru yang baik adalah guru yang profesional sebagai syarat bagi terselenggaranya proses pendidikan yang baik. Sedangkan kurikulum yang baik adalah kurikulum yang memiliki fleksibilitas dan daya antifersi yang memadai serta merupakan persyaratan bagi tercapainya pendidikan nasional.Usaha yang dilakukan pemerintah untuk mensosialisasikan Kurikulum dengan mengadakan penataran dan pelatihan bagi guru-guru. Penataran dan pelatihan bagi guru-guru digunakan sebagai sarana untuk 
meningkatkan kemampuan profesionalnya dalam mengelola proses pembelajaran di kelas. Guru dibimbing untuk merencanakan sebuah pembelajaran lengkap, seperti bahan ajar yang akan disajikan, konsep apa yang dibelajarkan, peralatan atau alat bantu ajar yang akan digunakan, media pembelajaran, metode penyampaian, jenis latihan untuk memperdalam pemahaman terhadap konsep yang baru dipelajari, evaluasi untuk mengukur keberhasilan pembelajaran. Tetapi kenyataan di lapangan berkata lain, setelah kembali dari pelatihan, jika guru tersebut tidak mendapat dorongan dan dukungan dari teman sejawat, termasuk kepala sekolah, dia tidak bersemangat untuk menerapkan hasil pelatihan. Akibat dari peristiwa semacam ini, guru tersebut tidak terdorong untuk menerapkan hasil pelatihan yang diperolehnya. Sehingga setelah kembali ke sekolah masing-masing penampilan guru kembali seperti sediakala.

Berdasarkan hal di atas sudah seharusnya dalam proses belajar mengajar seorang guru mampu memilih dan menggunakan metode pembelajaran yang sesuai, agar siswa dapat belajar secara efektif dan efisien sesuai tujuan yang diharapkan. Peranan guru dalam menentukan metode pembelajaran sangatlah penting, sehingga guru hanya sebagai fasilitator belajar. Untuk mengetahui seberapa jauh kemampuan guru dalammengelola kelas dengan proses belajar mengajar, maka penulis mengambil sampel dengan mengamati kemampuan guru khususnya untuk mata pelajaran Sejarah Kebudayaan Islam (SKI)pada MTs Negeri Baturaja. Berdasarkan pengamatan saya selama PPL di MTs Negeri Baturaja, Saya menemukan pokok permasalahan baik itu saya sendiri, ada juga sebagian guru mengalami kesulitan ketika proses belajar mengajar mengalami keributan, Salah satu yang dilakukan guru adalah marah ketika anak-anak ribut di kelas. Padahal marah bukanlah solusi untuk mengembalikan suasana kelas menjadi tertib, akan tetapi apabila guru memiliki kemampuan dalam mengelola kelas maka dengan mudah guru mengembalikan suasana kelas apabila mengalami gangguan. Adapun rumusan masalah dalam penelitian ini adalah bagaimana kemampuan guru Sejarah Kebudayaan Islam (SKI)dalam mengelola kelas di MTs Negeri Baturaja? Bagaimanaproses belajar mengajar pada mata pelajaran Sejarah Kebudayaan Islam (SKI) di MTs Negeri Baturaja? Adakah hubungan kemampuan guru dalam mengelola kelas dengan proses belajar mengajar pada mata pelajaran Sejarah Kebudayaan Islam (SKI) di MTs Negeri Baturaja? 


\section{Metode Penelitian}

\section{Jenis Penelitian}

Dalam melaksanakan penelitian ini, penulis menggunakan metode penelitian kuantitatif. Tujuannya adalah untuk memberikan Penelitian statistik, hubungan atau penjelasan. model penelitiannya adalah deskriptif analisis berdasarkan data-data yang diperoleh melalui penelitian kepustakaan dan penelitian lapangan.

\section{Populasi dan Sampel Penelitian}

Populasi

Adapun yang menjadi Populasi dalam penelitian ini adalahSiswa-Siswi MTs Negeri Baturaja yang berjumlah 633 siswa

Tabel 1. Populasi Penelitian

\begin{tabular}{|c|c|c|c|c|}
\hline \multirow{2}{*}{ No } & \multirow{2}{*}{ Kelas } & \multicolumn{2}{|c|}{ Jenis Kelamin } & \multirow{2}{*}{ Jumlah } \\
\cline { 3 - 4 } & & Laki-laki & Perempuan & \\
\hline 1 & VII. A & 14 & 19 & 33 \\
\hline 2 & VII. B & 20 & 14 & 34 \\
\hline 3 & VII. C & 10 & 23 & 33 \\
\hline 4 & VII. D & 20 & 12 & 32 \\
\hline 5 & VII. E & 12 & 21 & 33 \\
\hline 6 & VII.F & 18 & 15 & 33 \\
\hline 7 & VII. G & 19 & 14 & 33 \\
\hline 8 & VIII. A & 17 & 18 & 35 \\
\hline 9 & VIII. B & 17 & 17 & 34 \\
\hline 10 & VIII. C & 14 & 18 & 32 \\
\hline 11 & VIII. D & 18 & 16 & 34 \\
\hline 12 & VIII. E & 15 & 19 & 34 \\
\hline 13 & VIII.F & 19 & 15 & 34 \\
\hline 14 & IX. A & 16 & 17 & 33 \\
\hline 15 & IX. B & 15 & 18 & 33 \\
\hline 16 & IX. C & 14 & 19 & 33 \\
\hline 17 & IX. D & 12 & 21 & 33 \\
\hline 18 & IX.E & 15 & 18 & 33 \\
\hline 19 & IX.F & 15 & 19 & 34 \\
\hline & Total & 300 & 333 & 633 \\
\hline
\end{tabular}

Sumber : Dokumen MTs Negeri Baturaja Kab. OKU 2017/2018 


\section{Sampel Penelitian}

Dalam penelitian ini pengambilan sampel menggunakan teknik proportional stratified random sampling. Dalam pengambilan sampel, peneliti berpedoman pada Suharsimi Arikunto"Apabila subjeknya kurang dari 100, lebih baik diambil semua sehingga penelitiannya berupa penelitian populasi, jika jumlah subjeknya besar dapat diambil $10-15 \%$ atau $20-25 \%$ atau lebih, tergantung setidak-tidaknya dari:

1) Kemampuan peneliti dilihat dari waktu, tenaga dan dana.

2) Sempit luasnya wilayah pengamatan dari setiap subjek, karena hal ini menyangkut banyak sedikitnya dana.

3) Besar kecilnya resiko yang ditanggung oleh peneliti. Untuk penelitian yang beresiko besar, tentu saja jika sampel besar, hasilnya akan lebih baik.

Berdasarkan pendapat tersebut, maka pengambilan sampel dalam penelitian ini diambil $36 \%$ dari jumlah populasi yang berjumlah 633sehingga menjadi 228 siswa yang dijadikan Sampel penelitian.

Tabel 2. Sampel Penelitian

\begin{tabular}{|c|c|c|c|c|c|}
\hline \multirow{2}{*}{ No } & \multirow{2}{*}{ Kelas } & \multicolumn{2}{|c|}{ Jenis Kelamin } & \multirow{2}{*}{ Jumlah } & $\begin{array}{c}\text { Sampel } \\
\mathbf{3 6} \%\end{array}$ \\
\cline { 3 - 5 } & & $\begin{array}{c}\text { Laki- } \\
\text { laki }\end{array}$ & Perempuan & & 12 \\
\hline 1 & VII. A & 14 & 19 & 33 & 12 \\
\hline 2 & VII. B & 20 & 14 & 34 & 12 \\
\hline 3 & VII. C & 10 & 23 & 33 & 12 \\
\hline 4 & VII. D & 20 & 12 & 32 & 12 \\
\hline 5 & VII. E & 12 & 21 & 33 & 12 \\
\hline 6 & VII.F & 18 & 15 & 33 & 12 \\
\hline 7 & VII. G & 19 & 14 & 33 & 12 \\
\hline 8 & VIII. A & 17 & 18 & 35 & 12 \\
\hline 9 & VIII. B & 17 & 17 & 34 & 12 \\
\hline 10 & VIII. C & 14 & 18 & 32 & 12 \\
\hline 11 & VIII. D & 18 & 16 & 34 & 12 \\
\hline 12 & VIII. E & 15 & 19 & 34 & 12 \\
\hline 13 & VIII.F & 19 & 15 & 34 & \\
\hline
\end{tabular}




\begin{tabular}{|c|c|c|c|c|c|}
\hline 14 & IX. A & 16 & 17 & 33 & 12 \\
\hline 15 & IX. B & 15 & 18 & 33 & 12 \\
\hline 16 & IX. C & 14 & 19 & 33 & 12 \\
\hline 17 & IX. D & 12 & 21 & 33 & 12 \\
\hline 18 & IX.E & 15 & 18 & 33 & 12 \\
\hline 19 & IX.F & 15 & 19 & 34 & 12 \\
\hline & Total & 300 & 333 & 633 & 228 \\
\hline
\end{tabular}

\section{Analisa Data}

Data yang telah dikumpulkan dianalisis melalui dua tahap yaitu : Analisa pendahuluan, yaitu untuk mendiPenelitiankan karakteristik sampel serta mengklarifikasikannya. Analisa Uji Hipotesa, yaitu menguji benar tidaknya hipotesa yang telah disusun. Dalam pengujian hipotesa penulis menggunakan analisa statisik dengan menggunakan rumus Kai Kuadrat $\left(\mathrm{X}^{2}\right)$ sebagai berikut :

$$
X^{2}=\sum \frac{(f o-f t)^{2}}{f t}
$$

\section{Pembahasan}

\section{Kemampuan guru dalam Mengelola kelas di MTs Negeri Baturaja.}

Pengelolaan kelas terdiri dari dua kata, yaitu pengelolaan dankelas. Pengelolaan itu sendiri akar katanya adalah kelola ditambah awalan"pe" dan akhiran "an". Istilah lain dari kata pengelolaan adalah"manajemen".Manajemen adalah kata yang aslinya dari bahasa inggrisyaitu "Management", yang berarti ketatalaksanaan, tata pimpinan,pengelolaan dan pengertian umum menurut suharsimi adalahpengadsminitrasian, pengaturan dan penataan suatu kegiatan.Sedangkan kelas terkandung suatu pengertian, yaitu sekelompoksiswa, yang pada waktu yang sama menerima pengajaran yang sama dariguru yang sama. Menurut Sudirman N, pengelolaan kelas merupakan upaya dalammendayagunakan potensi kelas. Karena kelas mempunyai peranan dan fungsi tertentu dalam menunjang keberhasilan proses interaksi edukatif. 
Tabel 3. Distribusi Frekuensi Kemampuan guru dalam Mengelola kelas Di MTs Negeri Baturaja

\begin{tabular}{|c|c|c|c|c|c|}
\hline Interval & $X$ & $f$ & $x$, & $f x$, & $f\left(x^{\prime}\right)^{2}$ \\
\hline $86-88$ & 87 & 76 & 4 & 76 & 304 \\
\hline $83-85$ & 84 & 20 & 3 & 15 & 45 \\
\hline $80-82$ & 81 & 24 & 2 & 12 & 24 \\
\hline-79 & 78 & 20 & 1 & 5 & 5 \\
\hline $74-76$ & 75 & 24 & 0 & 0 & 0 \\
\hline $71-73$ & 72 & 16 & -1 & -4 & 4 \\
\hline $\begin{array}{ll}-70 \\
\end{array}$ & 69 & 20 & -2 & -10 & 20 \\
\hline $65-67$ & 66 & 20 & -3 & -15 & 45 \\
\hline $62-64$ & 63 & 8 & -4 & -8 & 32 \\
\hline Jumlah & & 228 & & 71 & 479 \\
\hline
\end{tabular}

Memperhatikan tabel di atas, maka diperoleh data: $\mathrm{i}=3, \mathrm{~N}=$ $57, \mathrm{M}^{\prime}=75, \Sigma \mathrm{fx}^{\prime}=71$, dan $\Sigma \mathrm{f}\left(\mathrm{x}^{\prime}\right)^{2}=479$. Dari rata-rata di atas, besarnya nilai mean dan standar deviasi dapat ditentukan dengan perhitungan sebagai berikut:

$$
\begin{aligned}
& M=75+3\left(\frac{71}{228}\right) \\
& =75+3(0,31) \\
& =75+0,93 \\
& =75,93 \\
& \begin{aligned}
S D & =3 \sqrt{\frac{479}{228}-\left(\frac{71}{228}\right)^{2}} \\
& =3 \sqrt{2,10-(0,31)^{2}} \\
& =3 \sqrt{2,10-0,10} \\
& =3 \sqrt{2} \\
& =3 x 1,41 \\
& =4,23
\end{aligned}
\end{aligned}
$$

Perhitungan-perhitungan di atas menunjukkan bahwa nilai ratarata $(\mathrm{Mx})=75,93$ dan nilai standar deviasi $(\mathrm{SDx})=4,23$ dari kedua nilai tersebut dapat ketahui batas-batas kategori tinggi, sedang, dan rendah dengan perhitungan sebagai berikut:

$$
\begin{aligned}
\text { Tinggi } & =75,93+4,23 \\
& =80,16 \approx 80 \text { ke atas } \\
\text { Sedang } & =\text { antara } 73 \text { sampai } 79 \\
\text { Rendah } & =75,93-4,23 \\
& =71,7 \approx 72 \text { ke bawah }
\end{aligned}
$$


Agar dapat diketahui Kemampuan guru dalam Mengelola kelas di MTs Negeri Baturaja, maka perlu diketahui presentase dari masing-masing kategori sebagaimana uraian tabel di bawah ini:

Tabel 4. Presentase Kemampuan guru dalam Mengelola kelas di MTs Negeri Baturaja

\begin{tabular}{|l|c|c|}
\hline $\begin{array}{c}\text { Kemampuan guru dalam Mengelola } \\
\text { kelas di MTs Negeri Baturaja }\end{array}$ & F & \% \\
\hline Tinggi $(86-88)$ & 76 & 33,33 \\
\hline Sedang $(71-85)$ & 104 & 45,62 \\
\hline Rendah $(62-70)$ & 48 & 21,05 \\
\hline Jumlah & $\mathbf{2 2 8}$ & $\mathbf{1 0 0}$ \\
\hline
\end{tabular}

Memperhatikan data di atas, maka secara umum dapat disimpulkan bahwa Kemampuan guru dalam Mengelola kelas di MTs Negeri Baturajadalam kategori sedang. Kesimpulan tersebut di dasarkan pada besarnya presentase kategori sedang yang mencapai $45,62 \%$, kategori tinggi yang mencapai $33,33 \%$, dan kategori rendah yang hanya mencapai $21,05 \%$.

Proses belajar mengajar pada mata pelajaran Sejarah Kebudayaan Islam (SKI) di MTs Negeri Baturaja

Tabel 5. Distribusi Frekuensi Proses belajar mengajar pada mata pelajaran Sejarah Kebudayaan Islam (SKI) di MTs Negeri Baturaja

\begin{tabular}{|cc|c|c|c|c|c|}
\hline \multicolumn{2}{|c|}{ Interval } & $\boldsymbol{X}$ & $\boldsymbol{F}$ & $\boldsymbol{x}$ & $\boldsymbol{f} \boldsymbol{x}^{\prime}$ & $\boldsymbol{f}\left(\boldsymbol{x}^{\prime}\right)^{\mathbf{2}}$ \\
\hline $92-$ & 95 & 93 & 48 & 5 & 60 & 300 \\
\hline $88-$ & 91 & 89 & 8 & 4 & 8 & 32 \\
\hline $84-$ & 87 & 85 & 8 & 3 & 6 & 18 \\
\hline $80-$ & - & 83 & 60 & 2 & 30 & 60 \\
\hline $76-$ & -79 & 77 & 36 & 1 & 9 & 9 \\
\hline $72-$ & -75 & 73 & 12 & 0 & 0 & 0 \\
\hline $68-71$ & 69 & 12 & -1 & -3 & 3 \\
\hline $64-67$ & 65 & 20 & -2 & -10 & 20 \\
\hline $60-63$ & 61 & 16 & -3 & -12 & 36 \\
\hline $56-59$ & 57 & 8 & -4 & -8 & 32 \\
\hline \multicolumn{2}{|c|}{ Jumlah } & & $\mathbf{2 2 8}$ & & $\mathbf{8 0}$ & $\mathbf{5 1 0}$ \\
\hline
\end{tabular}


Memperhatikan tabel di atas, maka diperoleh data: $\mathrm{i}=4, \mathrm{~N}=57$, $\mathrm{M}^{\prime}=73, \Sigma \mathrm{fx}^{\prime}=80$, dan $\Sigma \mathrm{f}\left(\mathrm{x}^{\prime}\right)^{2}=510$. Dari rata-rata di atas, besarnya nilai mean dan standar deviasi dapat ditentukan dengan perhitungan sebagai berikut:

$$
\begin{aligned}
M= & 73+4\left(\frac{80}{228}\right) \\
& =73+4(0,35) \\
& =73+1,4 \\
& =74,4 \\
S D & =4 \sqrt{\frac{510}{228}-\left(\frac{80}{228}\right)^{2}} \\
& =4 \sqrt{2,23-(0,35)^{2}} \\
& =4 \sqrt{2,23-0,122} \\
& =4 \sqrt{2,108} \\
& =4 x 1,451 \\
& =5,804
\end{aligned}
$$

Perhitungan-perhitungan di atas menunjukkan bahwa nilai ratarata $(\mathrm{Mx})=74,4$ dan nilai standar deviasi $(\mathrm{SDx})=5,804$ dari kedua nilai tersebut dapat ketahui batas-batas kategori tinggi, sedang, dan rendah dengan perhitungan sebagai berikut:

$$
\begin{aligned}
\text { Tinggi } & =74,4+5,804 \\
& =80,204 \approx 80 \text { ke atas } \\
\text { Sedang } & =\text { antara } 70 \text { sampai } 79 \\
\text { Rendah } & =74,4-5,804 \\
& =68,596 \approx 69 \text { ke bawah }
\end{aligned}
$$

Tabel 6. Presentase Proses belajar mengajar pada mata pelajaran Sejarah Kebudayaan Islam (SKI) di MTs Negeri

Baturaja

\begin{tabular}{|l|l|l|}
\hline $\begin{array}{c}\text { Proses belajar mengajar pada mata } \\
\text { pelajaran Sejarah Kebudayaan Islam (SKI) } \\
\text { di MTs Negeri Baturaja }\end{array}$ & \multicolumn{1}{|c|}{$\boldsymbol{f}$} & $\boldsymbol{\%}$ \\
\hline Tinggi $(89-95)$ & 52 & 22,81 \\
\hline Sedang (69-88) & 136 & 59,65 \\
\hline Rendah (59- 68) & 40 & 17,54 \\
\hline Jumlah & $\mathbf{2 2 8}$ & $\mathbf{1 0 0}$ \\
\hline Memperhatikan data di atas, maka secara umum dapat
\end{tabular}
disimpulkan bahwa Proses belajar mengajar pada mata pelajaran Sejarah Kebudayaan Islam (SKI) di MTs Negeri Baturajadalam 
kategori sedang. Kesimpulan tersebut di dasarkan pada besarnya presentase kategori sedang yang mencapai 59,65\%, kategori tinggi yang mencapai $22,81 \%$, dan kategori rendah yang hanya mencapai $17,54 \%$.

Hubungan kemampuan guru dalam Mengelola kelas dengan proses belajar mengajar pada mata pelajaran Sejarah Kebudayaan Islam (SKI) di MTs Negeri Baturaja.

Dalam mencari pengaruh tersebut di atas, maka penulis menggunakan uji Kai Kuadrat untuk mengetahui ada tidaknya efektivitas antara kedua variabel. Rumus yang digunakan adalah sebagai berikut :

$$
X^{2}=\Sigma \frac{(f o-f t)^{2}}{f t}
$$

Dengan mengamati 9 (sembilan) macam perubahan, yaitu TT, TS, TR, ST, SS, SR, RT, RS, dan RR, maka diperoleh tabel dibawah ini dengan data-data sebagai berikut :

\begin{tabular}{|c|c|c|c|c|}
\hline \multirow[t]{2}{*}{$\begin{array}{l}\text { Kemampuan guru } \\
\text { dalam Mengelola } \\
\text { kelas di MTs } \\
\text { Negeri Baturaja }\end{array}$} & \multicolumn{3}{|c|}{$\begin{array}{l}\text { Proses belajar mengajar pada mata } \\
\text { pelajaran Sejarah Kebudayaan } \\
\text { Islam (SKI) di MTs Negeri } \\
\text { Baturaja }\end{array}$} & \multirow[t]{2}{*}{ Jumlah } \\
\hline & Tinggi & Sedang & Rendah & \\
\hline $\begin{array}{l}\text { Tinggi } \\
\text { Sedang } \\
\text { Rendah }\end{array}$ & $\begin{array}{l}24 \\
24 \\
4\end{array}$ & $\begin{array}{l}44 \\
64 \\
32\end{array}$ & $\begin{array}{l}8 \\
16 \\
12\end{array}$ & $\begin{array}{l}76 \\
104 \\
48\end{array}$ \\
\hline Jumlah & 52 & 140 & 36 & 228 \\
\hline
\end{tabular}

Adapun perhitungan nilai $f t$ (frekuensi yang diharapkan dalam sampel sebagai pencerminan dari frekuensi yang diharapkan dalam populasi) adalah sebagai berikut :

$$
\begin{aligned}
& \text { Baris } 1: f t=\frac{52 \times 76}{228}=17,33 \\
& \text { Baris } 2: f t=\frac{52 \times 104}{228}=23,71 \\
& \text { Baris } 3: f t=\frac{52 \times 48}{228}=10,94 \\
& \text { Baris } 4: f t=\frac{140 \times 76}{228}=46,66
\end{aligned}
$$


Baris $5:$ ft $=\frac{140 \times 104}{228}=63,85$

Baris $6: \mathrm{ft}=\frac{140 \times 49}{228}=29,47$

Baris $7: f t=\frac{3622 \% 6}{228}=12$

Baris $8: \mathrm{ft}=\frac{36 \times 104}{329}=16,42$

Baris $9: \mathrm{ft}=\frac{36 \times 48}{228}=7,57$

Berdasarkan nilai ft pada tiap-tiap baris di atas, kemudian dihitung nilai-nlai yang berkaitan dengan penentuan Kai Kuadrat, maka diperoleh tabel perhitungan Kai Kuadrat sebagai berikut :

\begin{tabular}{|l|l|l|l|l|l|}
\hline Sel & $f o$ & $f t$ & $f o-f t$ & $(f o-f t)^{2}$ & $\frac{(f o-f t)^{2}}{F t}$ \\
\hline 1 & 6 & 4,33 & 1,67 & 2,788 & 0,643 \\
\hline 2 & 11 & 5,92 & 5,08 & 25,806 & 4,359 \\
\hline 3 & 2 & 2,73 & $-0,73$ & 0,532 & 0,194 \\
\hline 4 & 6 & 11,66 & $-5,66$ & 32.035 & 2,747 \\
\hline 5 & 16 & 15,96 & 0,04 & 0,001 & 0,000 \\
\hline 6 & 4 & 7,36 & $-3,36$ & 11,289 & 1,533 \\
\hline 7 & 1 & 3 & -2 & 2 & 0,666 \\
\hline 8 & 8 & 4,10 & 3,9 & 15,21 & 3,709 \\
\hline 9 & 3 & 1,89 & 1,11 & 1,232 & 0,651 \\
\hline \multicolumn{5}{|l}{} \\
$X^{2}=\Sigma \frac{(f o-f t)^{2}}{f t}=14,502$
\end{tabular}

Untuk mengetahui signifikansi $\mathrm{X}^{2}$ hasil penelitian terlebih dahulu harus ditentukan derajat kebebasannya. Rumus yang digunakan adalah sebagai berikut:

Derajat kebebasan $(\mathrm{db})=($ baris -1$)($ lajur -1$)$

Adapun penentuannya sebagai berikut :

$$
\begin{aligned}
\mathrm{db} & =(3-1)(3-1) \\
& =2.2 \\
& =4
\end{aligned}
$$

Setelah ditentukan derajat kebebasannya, maka akan ditentukan harga kritik Kai Kuadrat, baik pada taraf 5\% maupun $1 \%$. Berdasarkan tabel Kai Kuadrat diperoleh data bahwa nilai $\mathrm{X}^{2}$ tabel untuk $\mathrm{db}=4$, pada taraf $5 \%=9,488$, dan padataraf $1 \%=13,227$. Dari nilai $X^{2}$ hasil penelitian yang besarnya sama dengan 14,502 , harga kritik nilai $\mathrm{X}^{2}$ untuk taraf $5 \%$ dan $1 \%$ masing-masing sama dengan 
9,488 dan 13,277, maka dari ketiga nilai tersebut diperoleh perbandingan sebagai berikut :9,488 <14,502 > 13,277

1. Hipotesa nihil (Ho), yaitu: tidak adanya Hubungan yang signifikan (pasti) antara kemampuan guru dalam Mengelola kelas dengan proses belajar mengajar pada mata pelajaran Sejarah Kebudayaan Islam (SKI) di MTs Negeri Baturaja, ditolak.

2. Hipotesa kerja (Ho), yaitu: adanya Hubungan yang signifikan (pasti) antara kemampuan guru dalam Mengelola kelas dengan proses belajar mengajar pada mata pelajaran Sejarah Kebudayaan Islam (SKI) di MTs Negeri Baturaja, dapat diterima.

Berdasarkan pada keterangan tersebut, maka dalam penelitian ini (hasil penelitian) dapat diberikan kesimpulan bahwa ada Hubungan yang signifikan antara kemampuan guru dalam Mengelola kelas dengan proses belajar mengajar pada mata pelajaran Sejarah Kebudayaan Islam (SKI) di MTs Negeri Baturaja

\section{Simpulan}

Kemampuan guru dalam Mengelola kelas di MTs Negeri Baturaja dalam kategori sedang, yaitu mencapai $45,62 \%$. Hal ini berarti bahwa Kemampuan guru dalam Mengelola kelas di MTs Negeri Baturaja terlihat sudah cukup baik karena di dukung oleh kesungguhan guru dalam memberikan pemahaman dan bimbingan keagamaan kepada siswa tersebut.

Proses belajar mengajar pada mata pelajaran Sejarah Kebudayaan Islam (SKI) di MTs Negeri Baturaja dalam kategori sedang yaitu mencapai 59,65\%. Hal ini berarti bahwa Proses belajar mengajar pada mata pelajaran Sejarah Kebudayaan Islam (SKI) di MTs Negeri Baturaja terlihat sudah cukup baik karena di dukung oleh kebiasaan dan kegiatan siswa yang positif.

Ada Hubungan yang signifikan (pasti) antara kemampuan guru dalam Mengelola kelas dengan proses belajar mengajar pada mata pelajaran Sejarah Kebudayaan Islam (SKI) di MTs Negeri Baturaja. Berdasarkan penelitian diperoleh nilai $\mathrm{X}^{2}$ yang perbandingannya $9,488<14,502>13,277$. Jadi, baik pada taraf $5 \%$ maupun $1 \%$, Ha di terima, dan Ho di tolak. 


\section{DAFTAR PUSTAKA}

---------,. 2006. Prosedur Penelitian Suatu Pendekatan Praktek, Cet XIII, Jakarta : Rineka Cipta.

Abdul, Majid. 2005. Perencanaan Pembelajaran. Bandung: PT. Remaja Rosdakarya.

Ali, Suyuthi. 2002. Metodologi Penelitian Agama, Jakata : Raja Grapindo Persada.

Arikunto, Suharsimi. 1988. Pengelolaan Kelas dan Siswa Sebuah Pendekatan Evaluatif, Jakarta: Rajawali Press.

Bisri, Cik Hasan. 1998. Penuntun Penyusunan Rencana Penelitian Dan Penulisan Penelitian (Bidang Ilmu Agama Islam), Jakarta: Logos Wacana Ilmu.

Danim, Sudarwan. 2002. Menjadi Peneliti Kualitatif, Cet. I Bandung: Pustaka Pelajar.

Departemen Pendidikan dan Kebudayaan. 2002. Kamus Besar Bahasa Indonesia, Jakarta: Balai Pustaka.

Djamarah, Syaiful Bahri Aswan Zain. 2002. Strategi Belajar Mengajar, Cet.2, Jakarta: PT Rineka Cipta.

Djamarah, Syaiful Bahri. 2000. Guru dan Anak Didik Dalam Interaksi Edukatif , Cet. 1, Jakarta: Rineka Cipta.

Hadi Haryo, Amirul. 1998. Metodologi Penelitian Pendidikan, Bandung : Pustaka Setia.

Hadi, Sutrisno. 2006. Metodologi Research II, Yogyakarta : Andi Ofset.

Hadjar, Ibnu. 1996. Dasar-Dasar Metodologi Penelitian Kualitatif dalam Pendidikan, Jakarta : Raja Grafindo Persada. 
Lexy J, Meleong. 2000. Metodologi Penelitian Kualitatif, Bandung : PT. Remadja Rosda Karya.

Mulyasa. 2002. Kurikulum Berbasis Kompetensi. Bandung: PT. Remaja Rosdakarya.

Muslam, Pengelolaan Kelas dan Jurnal Pendidikan Ekonomi Islam, Semarang: Universitas Wahid Hasyim, November, 2003. Vol. 1

Nawawi, Hadari. 1989. Organisasi Sekolah dan pengelolaan Kelas, Cet.3, Jakarta: Haji Masagung.

Nurboko, Cholid dan Abu Ahmadi. 1997. Metodologi Penelitian, Jakarta : Bumi Aksara.

Rahmat, Djalaluddin. 1989. Psikologi Komunikasi, Bandung: Remaja Rosdakarya.

Sudijono, Anas. 2000. Pengantar Statistik Pendidikan, Jakarta : Rajawali Perss.

Sudjana, Nana dan Ibrahim. 2001. PenelitianDan Penilaian Dalam Pendidikan, Bandung: Sinar Baru Algesindo.

Sugiarto,. 2001. Teknik Sampling, Jakarta: PT. Gramedia Pustaka Utama.

Sugiyono,. 2003. Statistika Untuk Penelitian, Bandung: CV. Alfabeta.

Suhandini, Purwadi. 2003. Seminar dan Lokakarya Kurikulum BerbasisKompetensi dan Contextual Teaching and Learning Bagi Guru Guru.

Sukardi,. 2008. Metodologi Penelitian Pendidikan, Cet V, Jakarta: PT Bumi Aksara. 
Suryabrata, Sumadi. 1995. Metodologi Penelitian. cet. XI. Jakarta : PT. Raja Grafindo Persada.

Suryobroto, 1997. Proses Belajar Mengajar di Sekolah, Jakarta: Rineka Cipta. 